Chapter 7

\title{
Onco-Surgical Management of Liver Metastases from Colorectal Cancer
}

\author{
Irinel Popescu and Sorin Tiberiu Alexandrescu
}

Additional information is available at the end of the chapter

http://dx.doi.org/10.5772/65223

\begin{abstract}
Metastatic disease is the main cause of death in patients with colorectal cancer and the most frequent location of metastases is in the liver. The treatment of liver metastases of colorectal origin is multimodal and should be based on a multidisciplinary team decision. A systematic review of the literature revealed that the number of liver metastases, their maximum size, CEA level, advanced age of the patients, and presence of extrahepatic disease are no longer contraindications to liver resection. The resectability rate of colorectal liver metastases increased from 10 to almost $40 \%$, enabling 5year overall survival rates higher than $30 \%$. Short-term and long-term results achieved by simultaneous resection (SR) are similar to those achieved by staged resections in patients with synchronous colorectal liver metastases. Whenever possible, major hepatectomies should be replaced by ultrasound-guided limited liver resections, and primary tumor should be approached in a minimally invasive manner. Even initially unresectable colorectal liver metastases could be rendered resectable by an aggressive multimodal approach ("two-stage" hepatectomies, hepatectomy after portal vein embolization/ligation, resection after conversion chemotherapy, and hepatectomy associated with ablation). The presence of extrahepatic metastases is no longer a contraindication to liver resection, when extrahepatic disease is resectable. Repeat hepatectomy improves survival in patients with recurrent liver metastases.
\end{abstract}

Keywords: colorectal liver metastases, liver resection, survival, liver re-resection, unresectable liver metastases

\section{Introduction}

Colorectal cancer is the third cause of cancer-related death among adult patients [1]. Most of the patients with colorectal carcinoma decease due to the metastatic disease, and only a small 
percentage of these patients die due to the complications of the primary tumor or other comorbidities. Thus, in order to increase the life expectancy of patients with colorectal cancer, it is mandatory to improve the therapeutic strategies addressed to the metastatic colorectal cancer (mCRC). Because more than two thirds of the patients with colorectal cancer will develop liver metastases during their lifetime, it is obvious that the improvements in the treatment of liver metastases will translate into higher survival rates for these patients [2].

In this chapter, the current therapeutic strategies and the potential future trends in the oncosurgical treatment of colorectal liver metastases (CLMs) are presented.

\section{Treatment of liver metastases from colorectal cancer}

Nowadays, the treatment of colorectal liver metastases is multimodal, including liver resection, ablative therapies, chemotherapy, targeted therapies, and interventional radiology (radioembolization, chemoembolization, and portal vein embolization).

The most recent studies revealed that the highest survival rates have been achieved by complete resection of CLMs. Thus, an international database including more than 25,000 patients treated for CLMs (collected from 313 centers all over the world) revealed that the 5year overall survival (OS) rate achieved by liver resection was $42 \%$, while the 5 -year overall survival rate achieved by ablative therapies was $26 \%$ ( $p$ value $<0.001)$. Moreover, the 5 -year overall survival rate achieved by nonsurgical therapies was only $6 \%(p$ value $<0.001)$ [3].

\subsection{Pretherapeutic evaluation}

The main objectives of pretherapeutic evaluation are as follows: (1) confirmation of the presence of liver metastases, (2) assessment of extrahepatic metastases, and (3) evaluation of liver metastases resectability.

\subsubsection{Confirmation of liver metastases}

The presence of metastatic disease should be determined in all the patients diagnosed with colorectal cancer, at the time of their primary tumor diagnosis. The metastases identified at that time are considered as synchronous metastases, as well as the metastases detected during the operation addressed to the primary tumor (even when they were not revealed by preoperative evaluation). However, patients without synchronous metastases who underwent a curative-intent resection of the colorectal primary tumor should be periodically followed-up because up to $50 \%$ of them will develop metastases of colorectal origin [4]. These metastases are considered as metachronous colorectal metastases.

The evaluation performed to diagnose metastases from colorectal cancer is based on the CT scan of the thorax, abdomen, and pelvis. Sometimes, when the CT scan cannot rule out the presence of liver metastases, magnetic resonance imaging (MRI) could be useful because its specificity is higher than that of CT scan. 


\subsubsection{Assessment of extrahepatic metastases}

When the presence of extrahepatic disease is suspected, PET/CT should be performed in order to achieve a correct pretherapeutic evaluation. Moreover, in the past few years, the NCCN and ESMO guidelines suggested a routine performance of PET/CT scan in patients with resectable CLMs, to assess the extension of the disease [5].

Whenever the patient shows signs or symptoms suggestive for brain metastases, a head CT scan should be performed; similarly, when bone metastases are suspected, a bone scintigraphy is mandatory.

\subsubsection{Evaluation of liver metastases resectability}

The paradigm regarding the CLMs resectability has changed over the past two decades. Thus, in the early 1990s, the following situations were considered as contraindications for liver metastases resection: (a) the presence of more than four CLMs, (b) the size of liver metastases exceeding $5 \mathrm{~cm}$ of maximum diameter, (c) the presence of extrahepatic metastases, and (d) the advanced age of the patient (usually older than 70 years). During the past few years, one by one, each of these contraindications has been challenged by the results reported by different authors, based on smaller or larger cohorts of patients undergoing liver resection for CLMs exceeding these criteria.

At present, the largest database including patients with CLMs who underwent surgery with the intention of curative resection is LiverMetSurvey - an international registry of patients operated in 313 centers from 70 countries [3]. According to the report released by the managers of this database in December 2015, important observations regarding the usefulness of liver resection in different groups of patients were presented.

a. Although the survival rates achieved in patients with up to 3 CLMs were statistically significant, higher than those reported in patients with 4 or more CLMs, even in patients with more than 7 CLMs, the 5-year overall survival (OS) rate (achieved by curative-intent hepatectomy) was $26 \%$ [3]. These results suggested that the number of CLMs should not represent a contraindication to liver resection.

b. Regarding the size of CLMs, although the highest survival rates were achieved in the group of patients with liver metastases lower than $3 \mathrm{~cm}$, the 5 -year OS rates were higher than $35 \%$ also in patients with CLMs larger than $5 \mathrm{~cm} \mathrm{[3].}$

c. In patients with synchronous hepatic and extrahepatic metastases who underwent curative-intent surgery for both liver metastases and extrahepatic metastases, the 5-year OS rate was $22 \%$, significantly lower than those achieved in patients with liver-only metastases (5-year OS rate-44\%). However, the $22 \%$ survival rate in 5 years is obviously higher than the survival rates achieved by palliative treatment in patients with mCRC $(6 \%$ rate in 5 years according to the same database) [3]. Thus, the presence of concomitant extrahepatic disease is no longer considered as a contraindication to surgery, when the entire metastatic burden could be resected. 
d. Because the life expectancy increased significantly in most countries, more and more elderly patients, with a good clinical status, were diagnosed with CLMs. The results presented by the LiverMetSurvey database revealed that in patients older than 70 years, the 5-year OS rate was 38\% [3]. Thus, curative-intent hepatectomy is a worthwhile operation even in elderly patients and the age should not be considered as a contraindication for liver resection if the patient's performance status is good.

Because almost all the traditional contraindications to liver resection are no longer valid nowadays, the definition of the CLMs resectability should be based on a technical/practical point of view, taking into account what remains after liver resection.

At present, technical criteria of resectability include the anticipated ability to [6]

1. perform a margin-negative resection (R0);

2. preserve at least two contiguous liver segments with adequate vascular inflow, outflow, and biliary drainage;

3. preserve adequate future liver remnant (FLR) volume (at least $20-30 \%$ of functional liver volume in patients with normal liver and $30-35 \%$ of functional liver volume in patients pretreated with chemotherapy).

Moreover, in patients with a marginal FLR volume and/or underlying liver disease, the ability of FLR to function effectively should be assessed (frequently based on the appropriate regenerative response after portal vein embolization - PVE) [6].

Based on these criteria, the indications of liver resection for CLMs broadened over the past two decades, providing increased resectability rates in patients with CLMs. Thus, at present, it is considered that among the patients newly diagnosed with CLMs, almost $25 \%$ are initially resectable, whereas $75 \%$ are initially unresectable metastases.

Regarding the potentiality to resect CLMs, ESMO classified the patients with liver metastases in four groups [7]:

Group 0: Primarily, technically R0-resectable liver metastases and no "biological" relative contraindications (e.g., progressive disease during neo-adjuvant treatment, etc.).

Group 1: Potentially resectable metastatic disease with curative intention.

Group 2: Disseminated disease, technically "never"/unlikely resectable.

Group 3: Never-resectable metastatic disease.

\subsection{Initially resectable CLMs: Group 0}

Regarding the onco-surgical approach to CLMs, there are some differences between patients presenting synchronous CLMs (SCLMs) and patients who develop metachronous CLMs (MCLMs). These different strategies should mainly take into account the concomitant presence of the primary tumor and liver metastases in patients with SCLMs and the need to remove both tumor locations. 


\subsubsection{Synchronous colorectal liver metastases}

The first approach used in patients with SCLMs is consisted of two stages. During the first stage, the resection of the primary tumor is performed; and subsequently, usually $2-3$ months later, the resection of liver metastases is performed. This strategy is called delayed liver resection (DR) and theoretically presents a few advantages as presented below.

Due to the progress made in liver surgery and anesthesiology, in the late 1990s some centers started to perform, in selected patients, simultaneous resection of the primary tumor and liver metastases. The advantages postulated by the promoters of this simultaneous resection approach (SR) include the comfort of the patient (who avoids two surgical procedures under general anesthesia), the avoidance of progression to unresectability of CLMs (which is possible in the DR approach, during the interval between the two operations), and it is cost-effective [8$10]$.

However, the partisans of the DR approach advocate that this strategy is based on two theoretical assumptions: (a) DR avoids the association of two resections, thus reduces the risks of postoperative complications and mortality, and increases the safety of the procedure; (b) the biological behavior of the tumor could be assessed during the observation period between the two operations, thus allowing a better selection of the patients and improving the oncologic outcome [11, 12].

\subsubsection{Safety of the procedure}

Although the SR was looked upon with caution during the first few years after its launch, the results reported over the past two decades revealed that in patients with colon tumors and liver metastases requiring minor hepatectomies, the morbidity and mortality rates achieved by SR were similar to those observed in patients undergoing DR [13-16].

However, if the primary tumor is complicated with perforation or obstruction, due to the poor clinical condition of the patient, it is advisable to avoid the simultaneous resection and this situation is considered a common reason for DR.

In patients with rectal tumors and/or requiring major hepatectomies, the SR is still controversial because some authors reported significantly higher morbidity and mortality rates after SR in such instances than those shown by DR [16]. By these reasons, a consensus conference on CLMs management suggested caution in performing SR in such patients and recommended a staged approach (either delayed liver resection or liver-first approach) [17].

The liver-first approach is a new surgical strategy that consists of initial resection of liver metastases and subsequent resection of the primary tumor [18]. This approach is recommended especially in patients with border-line resectable CLMs (Figure 1) and/or rectal cancers. The advantages of this new approach over the classical delayed liver resection are as follows:

- When CLMs are border-line resectable at the time of the diagnosis, if a DR is scheduled, there is a major risk of metastases progression after the primary tumor resection, making the metastases unresectable and missing the chance of a potentially curative resection. This scenario could be avoided by the initial removal of CLMs. Because, in such situations, the 
complete resection of metastases usually requires a major hepatectomy (Figure 2), it is recommended to avoid the performance of a simultaneous resection in order to decrease the postoperative morbidity and mortality rates. Thus, the resection of the primary tumor could usually be postponed for few weeks, with a low risk of developing primary tumor complications.

- Moreover, if the primary tumor involves the rectum, in order to decrease the risk of local recurrence, it is advisable to perform preoperative radiotherapy. Because during radiotherapy the patient does not receive Oxaliplatin or Irinotecan and the interval between the start of radiotherapy and the time of rectal resection is usually longer than 3 months, the risk of CLMs progression to unresectability is high. Thus, the initial resection of CLMs avoids their progression to unresectability and allows the optimal treatment of the primary tumor, offering the highest chance of survival to these patients (Figure 3).
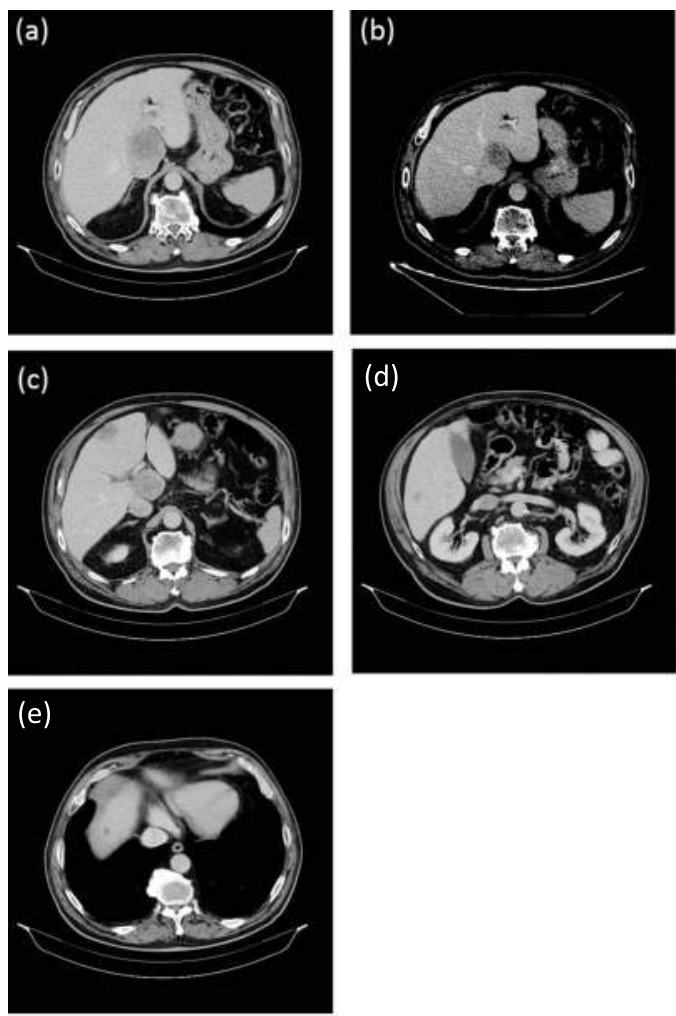

Figure 1. Abdominal CT scan of a 73-year-old patient with middle rectal adenocarcinoma and synchronous multiple liver metastases [5]: (a) segments 3 and 1 (caudate lobe) liver metastases; (b) the caudate lobe metastasis is adjacent to the inferior vena cava (IVC) and encases the middle hepatic vein; (c) segment 4 metastasis; (d) segment 6 metastasis; (e) segment 8 metastasis. 

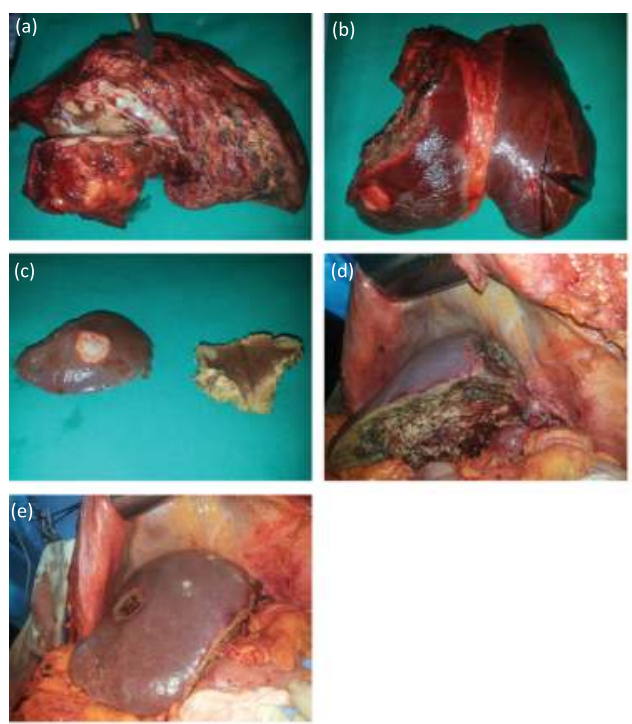

Figure 2. Liver-first approach (left hepatectomy extended to segment 1 and metastasectomies for the segment 6 and 8 CLMs): (a) specimen of left hepatectomy extended to segment 1, depicting the segment 1 metastasis with encasement of the middle hepatic vein; (b) the same specimen with segment 3 and 4 metastases; (c) specimens of metastasectomies for segment 6 and 8 CLMs; ( $d$ and e) intraoperative images of the remnant liver after complete resection of CLMs.
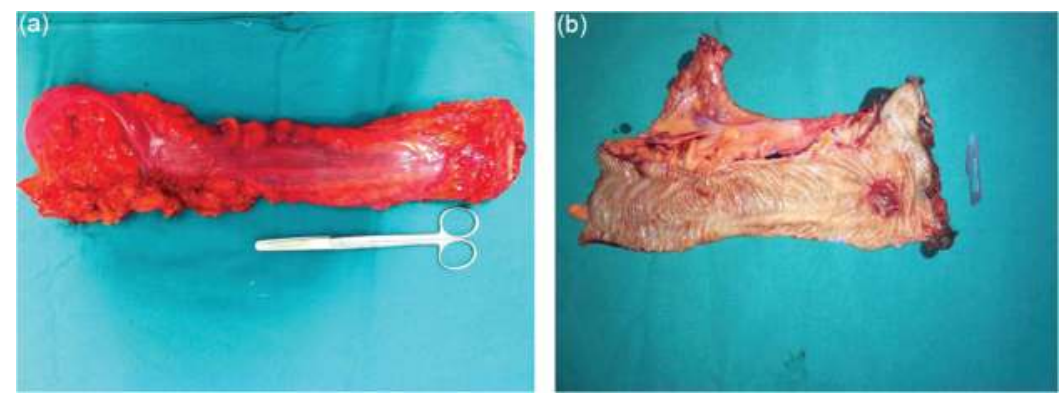

Figure 3. Specimen of low anterior rectal resection performed after short-course radiotherapy (the patient underwent radiotherapy after liver-first resection): (a) the specimen of low anterior rectal resection with total mesorectal excision; (b) the same specimen, transected (at least $2 \mathrm{~cm}$ distal resection margin).

\subsubsection{Oncologic outcome}

Regarding the postulated advantages offered by the "observation period," most of the series published until now revealed that the overall survival rates achieved by SR were similar to those achieved by staged resections $[8,13,19]$. Thus, the speculated advantage of "better selection of patients by DR" does not seem to be supported by the practice. This could be 
explained by the fact that most patients underwent chemotherapy between the two operations, and in the era of modern chemotherapy the progression-free survival rates are longer than 6 months [20]. Thus, the information provided by the "test of time" between the two operations is mitigated by the chemotherapy.

Moreover, a recent retrospective study, based on the results observed in patients enrolled in LiverMetSurvey, revealed that in patients with synchronous CLMs, the preoperative chemotherapy did not improve overall survival [21].

In conclusion, at present, most authors recommend the following approaches:

- Simultaneous resection (SR) in patients with uncomplicated colon tumors and synchronous CLMs requiring minor hepatectomies.

- Delayed resection (DR) in patients with obstruction or perforation of the primary tumor and synchronous CLMs.

- Liver-first approach in patients with border-line resectable CLMs (requiring major hepatectomies) and/or rectal carcinoma

\subsubsection{Metachronous colorectal liver metastases}

In patients with initially resectable metachronous CLMs, the up-front surgery could be recommended.

Preoperative chemotherapy may be useful especially in patients with a high clinical risk score (CRS). The clinical risk score is calculated by assigning one point to each of the following factors: multiple CLMs, metastases diameter larger than $5 \mathrm{~cm}$, CEA level higher than 200 $\mathrm{U} / \mathrm{ml}$, node-positive status of primary tumor (pathological), and disease-free interval less than 12 months [22]. A recent study revealed that neo-adjuvant chemotherapy significantly improved the survival rate in patients with a high clinical risk score (CRS 3-5), whereas in patients with a low risk profile (CRS 0-2) neo-adjuvant chemotherapy might not be beneficial [23].

However, the postoperative (adjuvant) chemotherapy is universally recommended at present, being considered almost mandatory after resection of CLMs, irrespective of the time of their appearance (synchronous or metachronous). The goals of postoperative chemotherapy are to increase both the disease-free survival (DFS) and overall survival (OS) rates [5].

\subsection{Potentially resectable CLMs: Group 1}

In this group, those patients who cannot undergo a complete resection of CLMs at the time of diagnosis, but are resectable by applying several onco-surgical strategies are included.

Thus, the goal of the treatment in this group should be conversion to resectability.

The following strategies will be able to render resectable the initially unresectable CLMs: 


\subsubsection{Liver resection following portal vein embolization or ligation}

When the complete resection of CLMs would leave in place at least two adjacent liver segments, but the FLR volume is not large enough to avoid the risk of postoperative liver failure, it might be possible to enlarge the volume of the FLR by performing portal vein ligation (PVL) or embolization (PVE) [24-26].

This strategy is especially useful in patients presenting CLMs confined to the right hemiliver and segment 4 . In such instances, frequently the volume of segments 2 and 3 is lower than 25$30 \%$ of functional liver volume (FLV). The right portal branch ligation or embolization could induce the hypertrophy of segments 2-3 (FLR), thus ensuring a volume of the FLR higher than $25-30 \%$ of FLV in $2-8$ weeks after the procedure $[24,27]$. The same therapeutic approach could be applied in patients with CLMs confined to the right hemiliver and presenting a small left hemiliver (the volume of segments $2-4$ is lower than $25-30 \%$ of the FLV).

The occlusion of the right portal branch will induce the atrophy of the right hemiliver and compensatory hypertrophy of the left hemiliver [28]. Thus, the ratio of FLR hypertrophy regularly ranges between 20 and 50\% and the volume of segments 2 and 3 (or of the left hemiliver) will often exceed $25-30 \%$ of the FLV [24, 27, 29, 30]. Consequently, a right trisectionectomy or right hepatectomy could be safely performed in more than $60 \%$ of the patients undergoing PVE/PVL, achieving the 5-year overall survival rates higher than $30 \%$ [24, 27, 30, 31].

The evaluation of FLR and FLV is usually based on software-assisted image postprocessing programs that provide volume measurements taking into account the actual anatomy of a specific patient (identified by CT scan), where FLV = volume of the entire liver - volume of the tumor. FLR represents the volume of the segments that are planned to be left in place after the scheduled curative liver resection.

Unfortunately, in almost one third of these patients, the complete resection of the metastatic disease could not be achieved, either due to the insufficient hypertrophy of the FLR or due to the development of new metastases in the FLR during the interval between PVL/PVE and the scheduled hepatectomy [24, 27, 32].

In order to overcome these drawbacks of portal vein occlusion, recently, a new strategy has been launched, aiming to increase the resectability rates in such patients.

\subsubsection{ALPPS (associating liver partition and portal vein ligation for staged hepatectomy)}

This surgical approach consists of association of the right portal branch ligation with transection of liver parenchyma during the same operative procedure. It was observed that this strategy enables a more rapid and greater hypertrophy of the FLR [33-35]. Thus, 7-10 days after this operation, the percentage of FLR volume hypertrophy ranges between 40 and $80 \%$ $[33,35]$, allowing the subsequent performance of R0 resection in almost $90-100 \%$ of the patients subjected to this new approach [36, 37]. 
Moreover, it was proved that in patients who failed to achieve adequate FLR hypertrophy after PVE, the performance of ALPPS was effective, inducing a FLR gain that allowed subsequent $\mathrm{R} 0$ resection $[37,38]$.

Because the hypertrophy of the FLR produced by ALPPS is 11-fold faster than those induced by PVL/PVE [34], this new strategy allows the complete resection of the tumor in a shorter period of time (7-14 days after the first stage), providing additional advantages, such as: (1) decreases the risk of disease progression between the two stages of the operation [36, 39]; (2) allows a more rapid recovery of the patient, decreasing the length of hospital stay [36]; and (3) the adjuvant chemotherapy could be started sooner than in patients undergoing PVL/PVE [36].

The main disadvantage of ALPPS is the high rate of major postoperative complications (27$41 \%)$ and mortality $(8-12.5 \%)$ [34, 35, 37, 40, 41]. To decrease the morbidity and mortality rates, some authors recommended avoiding the performance of ALPPS in patients older than 60 years and to circumvent the ligation of the right bile duct during the first operation [34, 4042]. Other factors associated with a dismal outcome are obesity, poststage one biliary fistula, and infected/bilious peritoneal fluid at the time of the second-stage operation [37].

However, a thorough selection of patients and a meticulous surgical technique could overcome these drawbacks, allowing the complete resection of initially unresectable CLMs in most patients scheduled for this approach.

\subsubsection{Two-stage liver resection}

This strategy is mainly recommended in patients presenting multiple bilobar CLMs, whose resection is not feasible during a single operative procedure because the volume of the remnant liver would be too small to avoid the postoperative liver failure [28, 43,44]. Thus, the goal of complete resection of CLMs could be achieved by combining two liver resections. During the first operation, the liver metastases from the FLR (usually left hemiliver or segments 2-3) are resected by metastasectomies, sparing as much as possible of the remnant functional liver. Consequently, the second-stage operation aims at the complete removal of CLMs, frequently by a right hepatectomy or a right trisectionectomy $[28,43,44]$.

Because the volume of the FLR is commonly insufficient (due to the liver resections already performed during the first operation), PVL could be carried out in the first stage. If the PVL was not performed during the first operation and the CT scan evaluation made before the second stage would reveal an insufficient volume of the FLR, a PVE could be underwent before the second surgery. Therefore, the hypertrophy of the FLR achieved by portal vein occlusion will allow the safe performance of the second operation, avoiding the risk of postoperative liver failure.

In the series reported until now, the resectability rates achieved by this approach ranged between 60 and $80 \%$, and the 3-year overall survival (OS) rates were higher than 35\% [28, 4345]. 


\subsubsection{Liver resection after downsizing chemotherapy}

This onco-surgical approach is usually performed in patients with few large metastases, whose initial resection would not preserve an adequate volume of the remnant liver parenchyma [28, $46,47]$. The goal of the treatment is to achieve the shrinkage of the tumors to such an extent that makes possible their resection.

In such patients with potentially resectable CLMs (Group 1), it is recommended to start an intense chemotherapy regimen, usually consisting of three chemotherapic drugs (5-FU, Oxaliplatin, and Irinotecan-FOLFOXIRI) and a monoclonal antibody [5]. In patients with RAS-wild-type tumors the use of an anti-EGFR (epidermal growth factor receptor) monoclonal antibody (Cetuximab or Panitumumab) is recommended, whereas in patients with RASmutant tumors the use of anti-VEGF (vascular endothelial growth factor) agent (Bevacizumab) is advocated.

The response to the treatment should be assessed every 2 months after the therapy commences (by CT scan or MRI) and the patient should be referred to the surgery as soon as the metastases became resectable. The continuation of the oncologic therapy beyond this time point could expose the patient to three dangerous scenarios:

- After the initial response to the oncologic therapy, the metastases could regrow, closing the "window of opportunity" for liver resection. Thus, the patient misses the chance of a potentially curative liver resection due to the useless continuation of chemotherapy [28].

- Due to the hepatic toxicity of both Oxaliplatin and Irinotecan, there is a high risk of an impaired liver function secondary to the long-course chemotherapy (usually more than six cycles) [48-50]. Oxaliplatin induces vascular disorders causing the appearance of the so-called "blue-liver," whereas Irinotecan induces steatohepatitis (NASH-nonalcoholic steatohepatitis) that generates the so-called "yellow-liver" [48-50]. When liver resection is performed in such patients, the morbidity and mortality rates increase dramatically, especially when major hepatectomies are needed [51-53]. Thus, to avoid the higher postoperative morbidity and mortality rates in patients whose CLMs were rendered to resectability after downsizing chemotherapy is mandatory to perform liver resection as soon as the metastases became resectable. Moreover, data derived from the LiverMetSurvey database revealed that the higher the number of chemotherapy cycles or lines, the lower the survival after liver resection [3].

- If the chemotherapy is prolonged too much, some liver metastases could become unidentifiable on CT scan or MRI. Unfortunately, this clinical/radiologic complete response is not equivalent to pathologic complete response, and it was well established that in more than $80 \%$ of cases the viable tumor cells are still present at the site of initial liver metastases (although they could not be found radiologically or intraoperatively) [54]. These lesions are called "vanishing metastases" and their initial sites should be resected in order to avoid their recurrence. However, this goal is difficult, especially when the metastases were originally located deep in the liver parenchyma. The metastases that could not be resected because they are not identified intraoperatively are called "missing metastases." In such instances, it is recommended to have a close follow-up of the patients in order to identify, as soon as possible, the "reappearance" of CLMs and perform their resection. In patients with "missing metasta- 
ses," intra-arterial chemotherapy could also be offered which seems to decrease the recurrence rates [55].

By using 5-FU and Oxaliplatin, the Paul Brousse group reported a rate of conversion to resectability of $13 \%[49,56]$, whereas more recent series reported even higher conversion rates (up to $28 \%$ ) by using intense chemotherapy regimens associated with targeted therapies [57].

In patients who underwent curative-intent resection of initially unresectable CLMs downsized by chemotherapy, the disease-free survival (DFS) and overall survival (OS) rates were statistically significant lower than those achieved in patients undergoing R0 resection for initially resectable CLMs $[28,56]$. However, the 5 -year OS rates (higher than $25 \%$ ) achieved by patients rendered to resectability after chemotherapy are statistically significant, higher than those reported in patients who received only palliative oncologic treatment $(6 \%$ at 5 years) $[3,56]$. These results justify the efforts to render the resectability of the initially unresectable CLMs by conversion chemotherapy [28].

Moreover, early tumor shrinkage (the decrease of CLMs size with more than $20 \%$, according to RECIST criteria, after 8 weeks of treatment) induced by the combination of chemotherapy with anti-EGFR agents (Cetuximab or Panitumumab) correlates with a higher rate of conversion to resectability $[58,59]$. Meanwhile, early tumor shrinkage is a strong predictor of favorable outcome, both in patients undergoing liver resection and in patients whose CLMs could not be rendered to resectability $[59,60]$. In patients who experienced early tumor shrinkage and underwent curative-intent liver resection, the 5-year OS rates were statistically significant, higher than those reported in patients rendered to resectability but who did not experience early tumor shrinkage [59].

\subsubsection{Liver resection associated with ablative treatment}

This strategy aims at the complete clearance of the liver and is especially recommended in patients with multiple bilobar CLMs that cannot be completely resected.

The ablative therapies are represented by radiofrequency ablation (RFA), microwave ablation and cryosurgery. The most widely used ablative therapy is RFA and most studies revealed that the local recurrence rates after RFA of CLMs smaller than $3 \mathrm{~cm}$ are similar to those achieved by liver resection [61].

For this reason, in patients with multiple bilobar CLMs the resection of the bulk metastatic burden (usually by a major hepatectomy - right hepatectomy or right trisectionectomy) and RFA of the small liver metastases from the remnant liver could be performed.

This approach is also of particular interest in patients with multiple CLMs, one of which is illlocated (e.g., in the proximity of hepato-caval confluence or portal vein bifurcation). Usually, the resection of such ill-located metastasis requires the removal of a large volume of normal liver parenchyma, increasing the risk of postoperative liver failure. Performing RFA for that metastasis avoids a major hepatectomy, sparing a large volume of nontumoral liver parenchyma, without compromising the oncologic outcome. In such instances, all the liver metastases could be resected, except for the ill-located one, which can be treated by ablation. 
This strategy (also called CARe-combined ablation and resection) has recently gained wide acceptance because current studies [62] revealed that the long-term outcomes achieved by CARe (5-year OS rates up to 37\%) are similar to those achieved by the other strategies used to render the resectability of the initially unresectable CLMs. Thus, the DFS and OS rates achieved by this approach are similar to those achieved by "two-stage" hepatectomies in the setting of multiple bilobar CLMs [63]. Moreover, the morbidity and mortality rates after CARe tend to be lower than those reported after "two-stage" liver resections [63].

However, these favorable long-term outcomes cannot be achieved if the diameter of the metastasis that will be ablated is larger than $3 \mathrm{~cm}$ or if the tumor is not completely ablated.

\subsection{Disseminated disease, technically "never"/unlikely resectable: Group 2}

In this group of patients, the therapeutic intention is rather palliative [5] and, obviously, the medical oncologist should start the treatment. According to the ESMO guidelines, the preferred option for the first line therapy is a cytotoxic doublet in combination with a targeted agent [5]. For symptomatic patients with RAS-wild type tumors, the association of FOLFOX/FOLFIRI with an anti-EGFR agent (Cetuximab or Panitumumab) seems to be the preferred therapy, whereas in the other patients the association of a cytotoxic doublet with Bevacizumab should be proposed.

When imaging re-evaluation shows evidence of favorable response of CLMs to the first-line treatment, the therapy should be reconsidered based on a multidisciplinary team decision.

Thus, if liver metastases became resectable, the patient should be referred to surgery. Even when CLMs were not rendered to resectability, oligometastatic patients could benefit from ablative therapies. In this situation, the ablation of the metastases could be performed percutaneously by an interventional radiologist. Although the DFS rates are lower than those achieved by liver resection, this approach could offer a period of chemotherapy discontinuation until the disease progresses [5].

In patients who did not become eligible for surgery or ablation, the de-escalation of the initial combination should be considered [5], in order to achieve a prolonged progression-free interval with good symptom control and, eventually, a higher overall survival rate.

\subsection{Never-resectable metastatic disease: Group 3}

This group includes the patients with bulk metastatic burden (frequently hepatic and extrahepatic) who cannot be rendered to resectability by anyone of the above-mentioned strategies.

The goal of the treatment should be the prevention of tumor progression as long as possible and the prolongation of life with minimal treatment load [5], without aiming maximal tumor shrinkage because conversion to resectability was ruled out ab initio. These goals might be achieved by either of the two approaches: (1) cytotoxic doublet (FOLFOX or FOLFIRI) usually associated with a monoclonal antibody, shifting to the other doublet on progression; (2) escalation strategy, starting with a fluoropyrimidine drug frequently associated with Bevacizumab, followed (on progression) by a cytotoxic doublet associated with a targeted agent [5]. 
At present, the interventional oncology techniques (e.g., selective internal radiation therapy, SIRT, and chemoembolization using drug-eluting beads Irinotecan, DEBIRI) are usually used in the second or the third-line therapy, but their efficacy is still under evaluation.

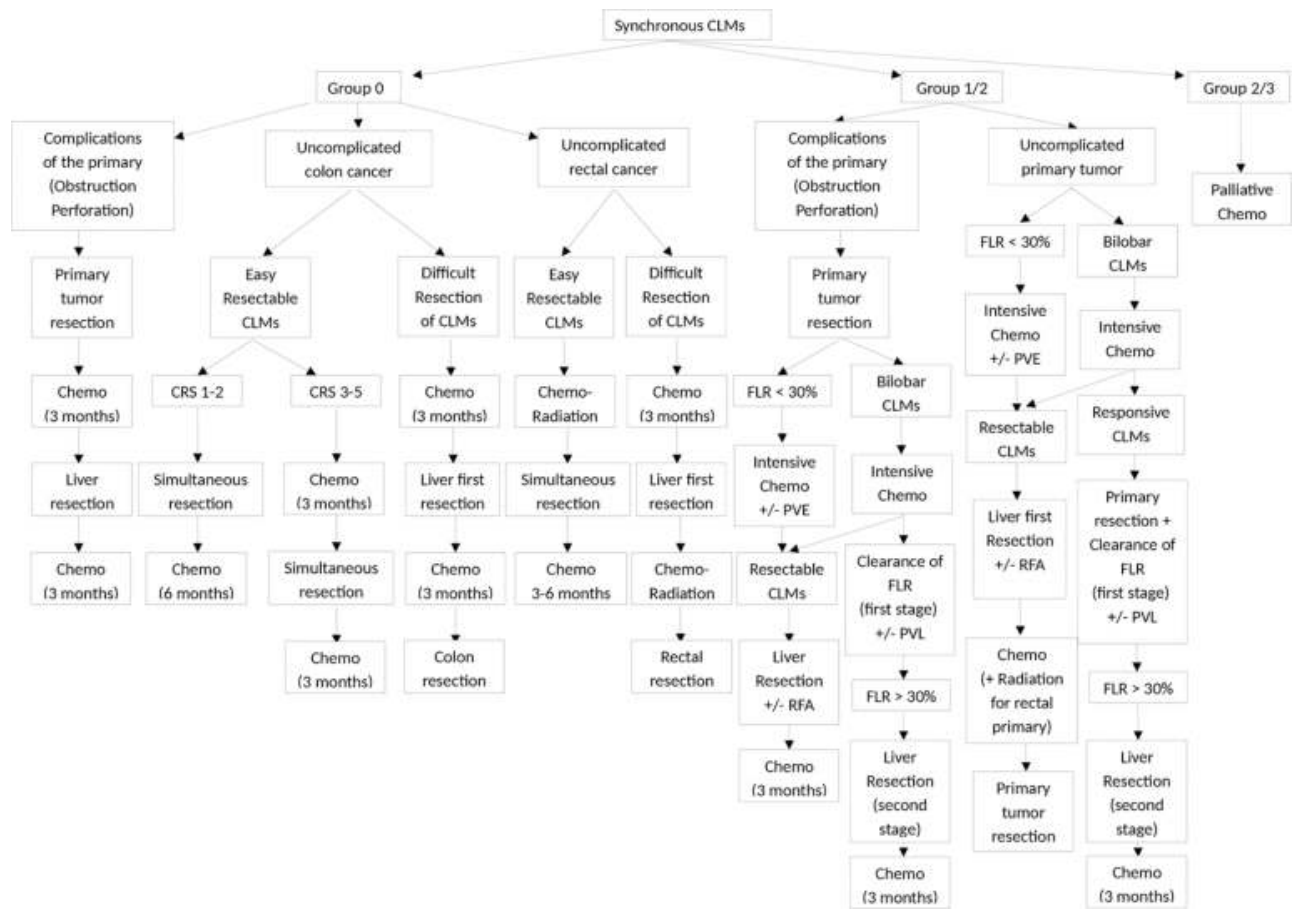

Table 1. Algorithm for onco-surgical management of patients with synchronous CLMs.

A meta-analysis revealed that DEBIRI achieved higher progression free survival (PFS) rates and better quality of life than standard oncologic therapy, when used in the second or the thirdline treatment (after disease progression on previous lines of systemic chemotherapy) [64]. Moreover, a randomized controlled trial compared the results of FOLFOX+Bevacizumab versus FOLFOX+DEBIRI+Bevacizumab in the first-line treatment of patients with initially unresectable CLMs. It was observed that the combination of FOLFOX, DEBIRI, and Bevacizumab achieved higher response rates, higher resectability rates, and significantly higher PFS rates than the standard combination of FOLFOX with Bevacizumab [65].

Thus, it is possible that future studies will establish a more prominent role for these therapies in the treatment of patients with initially unresectable CLMs.

In conclusion, the algorithm for onco-surgical management of CLMs is presented in Table 1 (synchronous CLMs) and Table 2 (metachronous CLMs). 


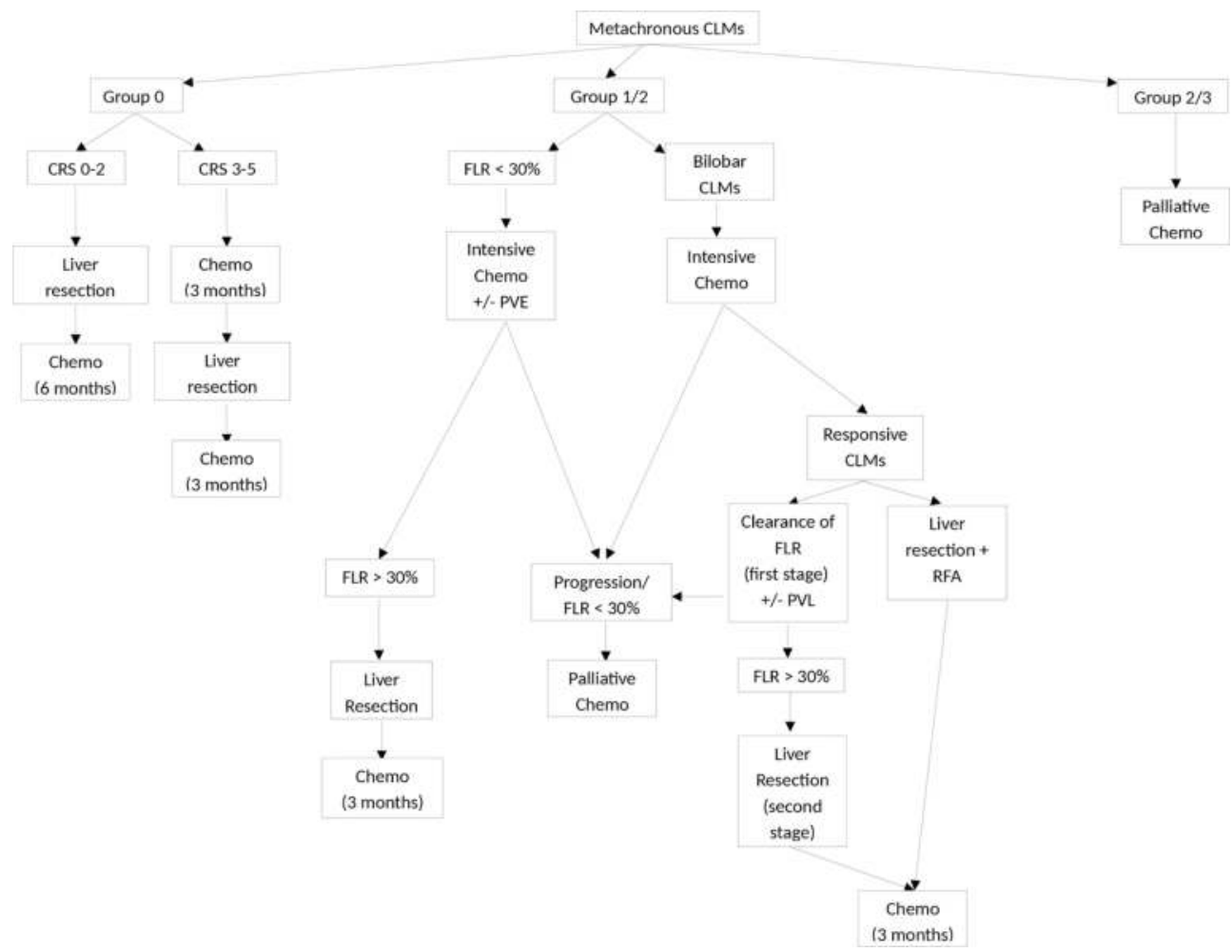

Table 2. Algorithm for onco-surgical management of patients with metachronous CLMs.

\subsection{Technical issues in surgery of CLMs}

During the past decade, the classical paradigms regarding the minimal resection margins that should be achieved, the adequate type of liver resection and the modality of surgical approach to liver metastases and primary tumor have been challenged by recent advances in surgery, anesthesiology, and medical oncology.

\subsubsection{Resection margins}

The classical paradigm regarding the width of resection margins postulated that a minimum margin of $10 \mathrm{~mm}$ is mandatory, to avoid the local recurrence. Later on, it was revealed that even narrower resection margins could be accepted if the metastasis is located in close proximity of bilio-vascular structures that should be preserved. Thus, Tanaka et al. reported a local recurrence rate of $2.8 \%$ in patients who underwent resection of CLMs with margins ranging between 2 and $4 \mathrm{~mm}$ and no local recurrence when resection margins were wider than $4 \mathrm{~mm}$ [66].

Therefore, at present, the resection of CLMs is recommended whenever a negative resection margin (R0) could be achieved [6]. 
Moreover, recent papers have revealed that in patients who primarily underwent R1 resection (CLMs located in contact with intrahepatic vascular structures that should be preserved) and subsequently modern postoperative chemotherapy, the overall survival rates were similar to those observed in patients who underwent $R 0$ resections ( $p$ value $>0.05)[67,68]$.

\subsubsection{Types of liver resections}

In the late 1990s, it was considered that anatomical liver resections offer superior long-term outcomes than nonanatomical hepatectomies because the rate of positive resection margins would be higher when nonanatomical resections were performed [69]. Later on, most authors revealed that the survival rates were similar irrespective of the type of liver resection, as long as complete resection (R0) of liver metastases could be achieved [22, 70].

Moreover, a considerable disadvantage of anatomical resections is related to the higher volume of nontumoral liver parenchyma that is removed, especially when major hepatectomies are performed. This issue has a negative impact on both the short-term and long-term outcomes. For example, a large retrospective study revealed that the number of liver segments resected and blood loss were the only predictors for both postoperative morbidity and mortality [71]. The authors concluded that reductions in the number of resected liver segments and blood loss are primarily responsible for the decrease in the perioperative mortality rate [71]. Moreover, because the recurrence rate of CLMs after an initial complete resection is up to $66 \%$ [72, 73] and the highest survival rates in patients with recurrent CLMs are achieved by liver reresections [74-76], it is obvious that a parenchyma-sparing hepatectomy should be always performed, in order to increase the possibility of subsequent liver resections.

Consequently, whenever possible, major liver resections should be replaced by parenchymasparing hepatectomies in order to decrease the perioperative morbidity and mortality rates and to offer the chance of repeat hepatectomies in patients with recurrent CLMs, thus prolonging their survival. For these reasons, at present, most authors recommend the performance of (ultrasound-guided) limited liver resections in patients with CLMs instead of major anatomical hepatectomies $[72,77,78]$.

\subsubsection{Surgical approach}

At present, laparoscopic colorectal resection offers similar morbidity, mortality, and survival rates as open resection of colorectal cancers [79]. Moreover, the laparoscopic approach decreases the blood loss, and ensures a more rapid postoperative recovery and shorter hospital stay [80]. By these reasons, in patients with synchronous CLMs, it is recommended to perform laparoscopic resection of the primary tumor and resection of liver metastases by an open approach, either during the sameoperative time(simultaneous resection) or as a staged procedure (delayed liver resection or liver-first resection). The simultaneous performance of colorectal resection by laparoscopy and liver resection by the open approach is particularly useful in patients presenting left colon or rectal tumor and liver metastases located in the right hemiliver [80].

Due to the technological progress made in the past few years, the rectal tumors have been approached more frequently by robotic surgery, and the morbidity, mortality, and survival 
rates are similar to those achieved by laparoscopic or open approach [81]. Because the anatomical structures of the pelvis are better visualized during robotic procedures, we recommend, in patients with rectal cancer and synchronous CLMs, the robotic resection of the primary tumor and resection of liver metastases by open surgery [82].

The progresses in laparoscopy also allowed the performance of liver resection by this approach. A meta-analysis revealed that laparoscopic liver resections enable lower blood loss and shorter hospital stay than open hepatectomies [83]. Moreover, a retrospective study reported a lower morbidity rate after laparoscopic hepatectomies than in patients undergoing liver resection by open approach [84]. Both of the above mentioned papers revealed that in patients undergoing laparoscopic liver resections for malignant diseases, the rates of complete resection (R0) were similar to those achieved in patients undergoing open hepatectomies [83, 84]. Regarding the long-term results achieved by laparoscopic resection of malignant liver tumors, the survival rates were similar to those achieved by open surgery [85-88]. Based on these outcomes, in the last period, in experienced centers, laparoscopic resection of CLMs is more frequently performed, even in patients scheduled for simultaneous resection of the primary tumor and liver metastases [82, 89, 90].

\subsection{Recurrent CLMs}

Almost two thirds of patients who underwent complete resection (R0) of CLMs will develop recurrent metastases, most of them during the first three years after the initial resection [72, 73]. The same therapeutic modalities are available to treat the recurrent CLMs and the highest survival rates are achieved by repeat liver resection [74-76, 91-93]. In the past few years, an increasing number of patients underwent a third, fourth, or even more liver resection and the available data suggest that the higher the number of repeated liver resections, the higher the survival rates $[3,75,93]$. Thus, the repeat liver resection is one of the most important therapeutic tools that contribute to a significant prolongation of overall survival in patients with CLMs.

Regarding the technical aspects, repeat liver resections presents some peculiar features, which could increase the risk of intraoperative and postoperative complications:

- Due to the previous liver resection, most patients develop perihepatic adhesions, thus increasing the risk of visceral (stomach, duodenum, and colon) or vascular (portal vein, inferior vena cava) injuries.

- The liver parenchyma is frailer as a consequence of the liver regeneration process (after the previous liver resection) and due to the hepatotoxicity induced by the prior chemotherapy. Thus, the amount of blood loss during the repeat liver resection could be higher than through the first hepatectomy, increasing the risk of postoperative complications.

- Because a part of the functional liver parenchyma has already been resected and previous chemotherapy could induce steatohepatitis or intrahepatic vascular injuries, the risk of postoperative liver failure after repeat hepatectomies is higher than after the first operation. To avoid this potentially fatal postoperative complication, it is advisable to perform parenchyma sparing hepatectomies both at the time of primary liver resection and during the subsequent hepatectomies. 
However, recent studies revealed that the morbidity and mortality rates after liver re-resection are not statistically significant, higher than those induced by the first operation [91].

\subsection{Surgery in patients with hepatic and extrahepatic colorectal metastases}

Although the presence of extrahepatic metastases was considered a major contraindication to liver resection for CLMs, the data presented during the last decade revealed that liver resection might be beneficial even in the presence of extrahepatic disease, when the entire metastatic burden could be resected [94, 95]. However, the performance of FDG-PET is mandatory prior to surgery, to assess the complete extent of metastatic disease.

Obviously, the survival rates are lower than those achieved in patients presenting liver-only colorectal metastases, but the 5-year overall survival rates up to $22 \%$ achieved in patients with concomitant extrahepatic disease seem to justify the efforts to accomplish the complete resection of metastatic disease [59].

The resection of the entire metastatic burden could be achieved during a single operation (liver resection associated with resection of intra-abdominal metastases - e.g., hepatic pedicle lymph nodes metastases, ovarian metastases, peritoneal metastases, adrenal metastases, etc.) or by staged operations (e.g., initial resection of liver metastases, followed by resection of lung metastases in a second stage).

In patients presenting hepatic and peritoneal metastases, along with liver resection, cytoreductive surgery (CRS) associated with hyperthermic intraperitoneal chemotherapy (HIPEC) should be offered, in order to achieve the highest survival rates [96, 97].

The favorable prognostic factors seem to be up to five liver metastases, extrahepatic disease confined only to the lung, primary tumor located on the left colon, and the CEA level lower than $10 \mathrm{ng} / \mathrm{ml}[98]$.

\section{Acknowledgements}

This study was financially supported by EEA-JRP-RO-NO-2013-1-0363, contract no. 4SEE/ 30.06.2014.

\section{Author details}

Irinel Popescu and Sorin Tiberiu Alexandrescu*

*Address all correspondence to: stalexandrescu@yahoo.com

"Dan Setlacec" Center of General Surgery and Liver Transplantation, Fundeni Clinical Institute, Bucharest, Romania 


\section{References}

[1] Jemal A, Murray T, Ward E, Samuels A, Tiwari RC, Ghafoor A, Feuer EJ, Thun MJ: Cancer statistics, 2005. CA Cancer J Clin 2005;55:10-30.

[2] McLoughlin JM, Jensen EH, Malafa M: Resection of colorectal liver metastases: current perspectives. Cancer Control 2006;13:32-41.

[3] LiverMet Survey: LiverMetSurvey Statistics December 2015. https://livermetsurvey manettis org:8443/SASStoredProcess/do.

[4] McMillan DC, McArdle CS: Epidemiology of colorectal liver metastases. SurgOncol 2007;16:3-5.

[5] Van CE, Cervantes A, Nordlinger B, Arnold D: Metastatic colorectal cancer: ESMO Clinical Practice Guidelines for diagnosis, treatment and follow-up. Ann Oncol 2014;25 Suppl 3:iii1-iii9.

[6] Adams RB, Aloia TA, Loyer E, Pawlik TM, Taouli B, Vauthey JN: Selection for hepatic resection of colorectal liver metastases: expert consensus statement. HPB (Oxford) 2013;15:91-103.

[7] Schmoll HJ, Van CE, Stein A, Valentini V, Glimelius B, Haustermans K, Nordlinger B, van de Velde CJ, Balmana J, Regula J, Nagtegaal ID, Beets-Tan RG, Arnold D, Ciardiello F, Hoff P, Kerr D, Kohne CH, Labianca R, Price T, Scheithauer W, Sobrero A, Tabernero J, Aderka D, Barroso S, Bodoky G, Douillard JY, El GH, Gallardo J, Garin A, GlynneJones R, Jordan K, Meshcheryakov A, Papamichail D, Pfeiffer P, Souglakos I, Turhal S, Cervantes A: ESMO Consensus Guidelines for management of patients with colon and rectal cancer. A personalized approach to clinical decision making. Ann Oncol 2012;23:2479-2516.

[8] Jaeck D, Bachellier P, Guiguet M, Boudjema K, Vaillant JC, Balladur P, Nordlinger B: Long-term survival following resection of colorectal hepatic metastases. Association Francaise de Chirurgie. Br J Surg 1997;84:977-980.

[9] Popescu I, Alexandrescu S: Hepatic metastasis of colorectal cancer-current therapeutic possibilities. Chirurgia (Bucur) 2010;105:155-169.

[10] Weber JC, Bachellier P, Oussoultzoglou E, Jaeck D: Simultaneous resection of colorectal primary tumour and synchronous liver metastases. Br J Surg 2003;90:956-962.

[11] Belghiti J: Métastases hépatiques synchroneset resecables des cancers colorectaux: y a$t$ il un délai minimum a respecter avant de faire la résectionhépatique. [Synchronous and resectable hepatic metastases of colorectal cancer: should there be a minimum delay before hepatic resection?] Ann Chir 1990;44:427-429.

[12] Nordlinger B, Guiguet M, Vaillant JC, Balladur P, Boudjema K, Bachellier P, Jaeck D: Surgical resection of colorectal carcinoma metastases to the liver. A prognostic scoring 
system to improve case selection, based on 1568 patients. Association Francaise de Chirurgie. Cancer 1996;77:1254-1262.

[13] Alexandrescu S, Hrehoret D, Ionel Z, Croitoru A, Anghel R, Popescu I: Simultaneous resection of the primary colorectal tumor and liver metastases-a safe and effective operation. Chirurgia (Bucur) 2012;107:298-307.

[14] Jaeck D, Bachellier P, Weber JC, Boudjema K, Mustun A, Paris F, Schaal JC, Wolf P: Stratégie chirurgicale dans le traitement des métastases hépatiques synchrones des cancers colorectaux. Analysed'unesérie de 59 malades opérés. Chirurgie 1999 [Surgical strategy in the treatment of synchronous hepatic metastases of colorectal cancers. Analysis of a series of 59 operated on patients];124:258-263.

[15] Luo Y, Wang L, Chen C, Chen D, Huang M, Huang Y, Peng J, Lan P, Cui J, Cai S, Wang J: Simultaneous liver and colorectal resections are safe for synchronous colorectal liver metastases. J Gastrointest Surg 2010;14:1974-1980.

[16] Reddy SK, Pawlik TM, Zorzi D, Gleisner AL, Ribero D, Assumpcao L, Barbas AS, Abdalla EK, Choti MA, Vauthey JN, Ludwig KA, Mantyh CR, Morse MA, Clary BM: Simultaneous resections of colorectal cancer and synchronous liver metastases: a multiinstitutional analysis. Ann Surg Oncol 2007;14:3481-3491.

[17] Adam R, De GA, Figueras J, Guthrie A, Kokudo N, Kunstlinger F, Loyer E, Poston G, Rougier P, Rubbia-Brandt L, Sobrero A, Tabernero J, Teh C, Van CE, Jean-Nicolas V: The oncosurgeryapproach to managing liver metastases from colorectal cancer: amultidisciplinary international consensus. Oncologist 2012;17(10):1225-39.

[18] Mentha G, Roth AD, Terraz S, Giostra E, Gervaz P, Andres A, Morel P, Rubbia-Brandt L, Majno PE: 'Liver first' approach in the treatment of colorectal cancer with synchronous liver metastases. Dig Surg 2008;25:430-435.

[19] Mayo SC, Pulitano C, Marques H, Lamelas J, Wolfgang CL, de SW, Choti MA, Gindrat I, Aldrighetti L, Barrosso E, Mentha G, Pawlik TM: Surgical management of patients with synchronous colorectal liver metastasis: a multicenter international analysis. J Am Coll Surg 2013;216:707-716.

[20] Reddy SK, Barbas AS, Clary BM: Synchronous colorectal liver metastases: is it time to reconsider traditional paradigms of management? Ann Surg Oncol 2009;16:2395-2410.

[21] Bonney GK, Coldham C, Adam R, Kaiser G, Barroso E, Capussotti L, Laurent C, Verhoef C, Nuzzo G, Elias D, Lapointe R, Hubert C, Lopez-Ben S, Krawczyk M, Mirza DF: Role of neoadjuvant chemotherapy in resectable synchronous colorectal liver metastasis; An international multi-center data analysis using LiverMetSurvey. J Surg Oncol 2015;111:716-724.

[22] Fong Y, Fortner J, Sun RL, Brennan MF, Blumgart LH: Clinical score for predicting recurrence after hepatic resection for metastatic colorectal cancer: analysis of 1001 consecutive cases. Ann Surg 1999;230:309-318. 
[23] Ayez N, van der Stok EP, Grunhagen DJ, Rothbarth J, van ME, Eggermont AM, Verhoef $\mathrm{C}$ : The use of neo-adjuvant chemotherapy in patients with resectable colorectal liver metastases: clinical risk score as possible discriminator. Eur J Surg Oncol 2015;41:859_ 867.

[24] Azoulay D, Castaing D, Smail A, Adam R, Cailliez V, Laurent A, Lemoine A, Bismuth $\mathrm{H}$ : Resection of nonresectable liver metastases from colorectal cancer after percutaneous portal vein embolization. Ann Surg 2000;231:480-486.

[25] Makuuchi M, Thai BL, Takayasu K, Takayama T, Kosuge T, Gunven P, Yamazaki S, Hasegawa H, Ozaki H: Preoperative portal embolization to increase safety of major hepatectomy for hilar bile duct carcinoma: a preliminary report. Surgery 1990;107:521527.

[26] Popescu I, David L, Brasoveanu V, Boros M, Hrehoret D: Two-stage hepatectomy: an analysis of a single center's experience. MagySeb 2006;59:184-189.

[27] Popescu I, Alexandrescu S, Croitoru A, Boros M: Strategies to convert to resectability the initially unresectable colorectal liver metastases. Hepatogastroenterology 2009;56:739-744.

[28] PopescuI, Alexandrescu ST: Surgical options for initially unresectable colorectal liver metastases. HPB Surg 2012;2012:454026.

[29] Farges O, Belghiti J, Kianmanesh R, Regimbeau JM, Santoro R, Vilgrain V, Denys A, Sauvanet A: Portal vein embolization before right hepatectomy: prospective clinical trial. Ann Surg 2003;237:208-217.

[30] Jaeck D, Bachellier P, Nakano H, Oussoultzoglou E, Weber JC, Wolf P, Greget M: One or two-stage hepatectomy combined with portal vein embolization for initially nonresectable colorectal liver metastases. Am J Surg 2003;185:221-229.

[31] Abdalla EK, Hicks ME, Vauthey JN: Portal vein embolization: rationale, technique and future prospects. Br J Surg 2001;88:165-175.

[32] Abulkhir A, Limongelli P, Healey AJ, Damrah O, Tait P, Jackson J, Habib N, Jiao LR: Preoperative portal vein embolization for major liver resection: a meta-analysis. Ann Surg 2008;247:49-57.

[33] de SE, Alvarez FA, Ardiles V: How to avoid postoperative liver failure: a novel method. World J Surg 2012;36:125-128.

[34] Schadde E, Ardiles V, Slankamenac K, Tschuor C, Sergeant G, Amacker N, Baumgart J, Croome K, Hernandez-Alejandro R, Lang H, de SE, Clavien PA: ALPPS offers a better chance of complete resection in patients with primarily unresectable liver tumors compared with conventional-staged hepatectomies: results of a multicenter analysis. World J Surg 2014;38:1510-1519.

[35] Schnitzbauer AA, Lang SA, Goessmann H, Nadalin S, Baumgart J, Farkas SA, FichtnerFeigl S, Lorf T, Goralcyk A, Horbelt R, Kroemer A, Loss M, Rummele P, Scherer MN, 
Padberg W, Konigsrainer A, Lang H, Obed A, Schlitt HJ: Right portal vein ligation combined with in situ splitting induces rapid left lateral liver lobe hypertrophy enabling 2-staged extended right hepatic resection in small-for-size settings. Ann Surg 2012;255:405-414.

[36] Tanaka K, Matsuo K, Murakami T, Kawaguchi D, Hiroshima Y, Koda K, Endo I, Ichikawa $\mathrm{Y}$, Taguri M, Tanabe M: Associating liver partition and portal vein ligation for staged hepatectomy (ALPPS): short-term outcome, functional changes in the future liver remnant, and tumor growth activity. Eur J Surg Oncol 2015;41:506-512.

[37] Truant S, Scatton O, Dokmak S, Regimbeau JM, Lucidi V, Laurent A, Gauzolino R, Castro BC, Pequignot A, Donckier V, Lim C, Blanleuil ML, Brustia R, Le Treut YP, Soubrane O, Azoulay D, Farges O, Adam R, Pruvot FR: Associating liver partition and portal vein ligation for staged hepatectomy (ALPPS): impact of the inter-stages course on morbi-mortality and implications for management. Eur J Surg Oncol 2015;41:674682.

[38] Tschuor C, Croome KP, Sergeant G, Cano V, Schadde E, Ardiles V, Slankamenac K, Claria RS, de SE, Hernandez-Alejandro R, Clavien PA: Salvage parenchymal liver transection for patients with insufficient volume increase after portal vein occlusion an extension of the ALPPS approach. Eur J Surg Oncol 2013;39:1230-1235.

[39] de SE, Clavien PA: Playing Play-Doh to prevent postoperative liver failure: the "ALPPS" approach. Ann Surg 2012;255:415-417.

[40] Dokmak S, Belghiti J: Which limits to the "ALPPS" approach? Ann Surg 2012;256:e6e7.

[41] Nadalin S, Capobianco I, Li J, Girotti P, Konigsrainer I, Konigsrainer A: Indications and limits for associating liver partition and portal vein ligation for staged hepatectomy (ALPPS). Lessons learned from 15 cases at a single centre. Z Gastroenterol 2014;52:3542.

[42] Li J, Girotti P, Konigsrainer I, Ladurner R, Konigsrainer A, Nadalin S: ALPPS in right trisectionectomy: a safe procedure to avoid postoperative liver failure? J Gastrointest Surg 2013;17:956-961.

[43] Adam R, Laurent A, Azoulay D, Castaing D, Bismuth H: Two-stage hepatectomy: A planned strategy to treat irresectable liver tumors. Ann Surg 2000;232:777-785.

[44] Jaeck D, Oussoultzoglou E, Rosso E, Greget M, Weber JC, Bachellier P: A two-stage hepatectomy procedure combined with portal vein embolization to achieve curative resection for initially unresectable multiple and bilobar colorectal liver metastases. Ann Surg 2004;240:1037-1049.

[45] Faitot F, Soubrane O, Wendum D, Sandrini J, Afchain P, Balladur P, De GA, Scatton O: Feasibility and survival of 2-stage hepatectomy for colorectal metastases: definition of a simple and early clinicopathologic predicting score. Surgery 2015;157:444-453. 
[46] Adam R, Avisar E, Ariche A, Giachetti S, Azoulay D, Castaing D, Kunstlinger F, Levi F, Bismuth F: Five-year survival following hepatic resection after neoadjuvant therapy for nonresectable colorectal. Ann Surg Oncol 2001;8:347-353.

[47] Bismuth H, Adam R, Levi F, Farabos C, Waechter F, Castaing D, Majno P, Engerran L: Resection of nonresectable liver metastases from colorectal cancer after neoadjuvant chemotherapy. Ann Surg 1996;224:509-520.

[48] Aloia T, Sebagh M, Plasse M, Karam V, Levi F, Giacchetti S, Azoulay D, Bismuth H, Castaing D, Adam R: Liver histology and surgical outcomes after preoperative chemotherapy with fluorouracil plus oxaliplatin in colorectal cancer liver metastases. J Clin Oncol 2006;24:4983-4990.

[49] Mehta NN, Ravikumar R, Coldham CA, Buckels JA, Hubscher SG, Bramhall SR, Wigmore SJ, Mayer AD, Mirza DF: Effect of preoperative chemotherapy on liver resection for colorectal liver metastases. Eur J Surg Oncol 2008;34:782-786.

[50] Rubbia-Brandt L, Audard V, Sartoretti P, Roth AD, Brezault C, Le CM, Dousset B, Morel P, Soubrane O, Chaussade S, Mentha G, Terris B: Severe hepatic sinusoidal obstruction associated withoxaliplatin-based chemotherapy in patients with metastatic colorectal cancer. Ann Oncol 2004;15:460-466.

[51] Karoui M, Penna C, Amin-Hashem M, Mitry E, Benoist S, Franc B, Rougier P, Nordlinger B: Influence of preoperative chemotherapy on the risk of major hepatectomy for colorectal liver metastases. Ann Surg 2006;243:1-7.

[52] Nakano H, Oussoultzoglou E, Rosso E, Casnedi S, Chenard-Neu MP, Dufour P, Bachellier P, Jaeck D: Sinusoidal injury increases morbidity after major hepatectomy in patients with colorectal liver metastases receiving preoperative chemotherapy. Ann Surg 2008;247:118-124.

[53] Vauthey JN, Pawlik TM, Ribero D, Wu TT, Zorzi D, Hoff PM, Xiong HQ, Eng C, Lauwers GY, Mino-Kenudson M, Risio M, Muratore A, Capussotti L, Curley SA, Abdalla EK: Chemotherapy regimen predicts steatohepatitis and an increase in 90-day mortality after surgery for hepatic colorectal metastases. J Clin Oncol 2006;24:2065-2072.

[54] Benoist S, Brouquet A, Penna C, Julie C, El Hajjam M, Chagnon S, Mitry E, Rougier P, Nordlinger B: Complete response of colorectal liver metastases after chemotherapy: does it mean cure? J Clin Oncol 2006;24:3939-3945.

[55] Elias D, Goere D, Boige V, Kohneh-Sharhi N, Malka D, Tomasic G, Dromain C, Ducreux M: Outcome of posthepatectomy-missing colorectal liver metastases after complete response to chemotherapy: impact of adjuvant intra-arterial hepatic oxaliplatin. Ann Surg Oncol 2007;14:3188-3194.

[56] Adam R, Delvart V, Pascal G, Valeanu A, Castaing D, Azoulay D, Giacchetti S, Paule B, Kunstlinger F, Ghemard O, Levi F, Bismuth H: Rescue surgery for unresectable 
colorectal liver metastases downstaged by chemotherapy: a model to predict long-term survival. Ann Surg 2004;240:644-657.

[57] Malik H, Khan AZ, Berry DP, Cameron IC, Pope I, Sherlock D, Helmy S, Byrne B, Thompson M, Pulfer A, Davidson B: Liver resection rate following downsizing chemotherapy with cetuximab in metastatic colorectal cancer: UK retrospective observational study. Eur J Surg Oncol 2015;41:499-505.

[58] Douillard JY, Siena S, Peeters M, Koukakis R, Terwey JH, Tabernero J: Impact of early tumour shrinkage and resection on outcomes in patients with wild-type RAS metastatic colorectal cancer. Eur J Cancer 2015;51:1231-1242.

[59] Modest DP, Laubender RP, Stintzing S, Giessen C, Schulz C, Haas M, Mansmann U, Heinemann V: Early tumor shrinkage in patients with metastatic colorectal cancer receiving first-line treatment with cetuximab combined with either CAPIRI or CAPOX: an analysis of the German AIO KRK 0104 trial. Acta Oncol 2013;52:956-962.

[60] Piessevaux H, Buyse M, Schlichting M, Van CE, Bokemeyer C, Heeger S, Tejpar S: Use of early tumor shrinkage to predict long-term outcome in metastatic colorectal cancer treated with cetuximab. J Clin Oncol 2013;31:3764-3775.

[61] Wang X, Sofocleous CT, Erinjeri JP, Petre EN, Gonen M, Do KG, Brown KT, Covey AM, Brody LA, Alago W, Thornton RH, Kemeny NE, Solomon SB: Margin size is an independent predictor of local tumor progression after ablation of colon cancer liver metastases. Cardiovasc Intervent Radiol 2013;36:166-175.

[62] Evrard S, Poston G, Kissmeyer-Nielsen P, Diallo A, Desolneux G, Brouste V, Lalet C, Mortensen F, Stattner S, Fenwick S, Malik H, Konstantinidis I, DeMatteo R, D'Angelica M, Allen P, Jarnagin W, Mathoulin-Pelissier S, Fong Y: Combined ablation and resection (CARe) as an effective parenchymal sparing treatment for extensive colorectal liver metastases. PLoS One 2014;9:e114404.

[63] Faitot F, Faron M, Adam R, Elias D, Cimino M, Cherqui D, Vibert E, Castaing D, Cunha AS, Goere D: Two-stage hepatectomy versus 1-stage resection combined with radiofrequency for bilobar colorectal metastases: a case-matched analysis of surgical and oncological outcomes. Ann Surg 2014;260:822-827.

[64] Richardson AJ, Laurence JM, Lam VW: Transarterial chemoembolization with irinotecan beads in the treatment of colorectal liver metastases: systematic review. J Vasc Interv Radiol 2013;24:1209-1217.

[65] Martin RC, Scoggins CR, Schreeder M, Rilling WS, Laing CJ, Tatum CM, Kelly LR, Garcia-Monaco RD, Sharma VR, Crocenzi TS, Strasberg SM: Randomized controlled trial of irinotecan drug-eluting beads with simultaneous FOLFOX and bevacizumab for patients with unresectable colorectal liver-limited metastasis. Cancer 2015 Oct 15;121(20):3649-58

[66] Kokudo N, Miki Y, Sugai S, Yanagisawa A, Kato Y, Sakamoto Y, Yamamoto J, Yamaguchi T, Muto T, Makuuchi M: Genetic and histological assessment of surgical margins in 
resected liver metastases from colorectal carcinoma: minimum surgical margins for successful resection. Arch Surg 2002;137:833-840.

[67] de Haas RJ, Wicherts DA, Flores E, Azoulay D, Castaing D, Adam R: R1 resection by necessity for colorectal liver metastases: is it still a contraindication to surgery? Ann Surg 2008;248:626-637.

[68] Eveno C, Karoui M, Gayat E, Luciani A, Auriault ML, Kluger MD, Baumgaertner I, Baranes L, Laurent A, Tayar C, Azoulay D, Cherqui D: Liver resection for colorectal liver metastases with peri-operative chemotherapy: oncological results of R1 resections. HPB (Oxford) 2013;15:359-364.

[69] Scheele J, Altendorf-Hofmann A: Surgical treatment of liver metastases; In Blumgart LH, Fong Y, (eds): Surgery of the liver and biliary tract. London, W. B. Saunders, 2000, pp 1475-1502.

[70] Kokudo N, Tada K, Seki M, Ohta H, Azekura K, Ueno M, Matsubara T, Takahashi T, Nakajima T, Muto T: Anatomical major resection versus nonanatomical limited resection for liver metastases from colorectal carcinoma. Am J Surg 2001;181:153-159.

[71] Jarnagin WR, Gonen M, Fong Y, Dematteo RP, Ben-Porat L, Little S, Corvera C, Weber $\mathrm{S}$, Blumgart LH: Improvement in perioperative outcome after hepatic resection: analysis of 1,803 consecutive cases over the past decade. Ann Surg 2002;236:397-406.

[72] Taylor I, Mullee MA, Campbell MJ: Prognostic index for the development of liver metastases in patients with colorectal cancer. Br J Surg 1990;77:499-501.

[73] Topal B, Kaufman L, Aerts R, Penninckx F: Patterns of failure following curative resection of colorectal liver metastases. Eur J SurgOncol 2003;29:248-253.

[74] Alexandrescu S, Diaconescu A, Anghel R, Croitoru A, Boros M, Ionescu M, Popescu I: Surgical treatment of recurrent colorectal cancer metastases; Chirurgia (Bucur) 2008; Suppl. 1: pp S34-S35.

[75] Takahashi M, Hasegawa K, Oba M, Aoki T, Sakamoto Y, Sugawara Y, Kokudo N: Repeat resection leads to long-term survival: analysis of 10-year follow-up of patients with colorectal liver metastases. Am J Surg 2015 Nov;210(5):904-10.

[76] Vigano L, Capussotti L, Lapointe R, Barroso E, Hubert C, Giuliante F, Ijzermans JN, Mirza DF, Elias D, Adam R: Early recurrence after liver resection for colorectal metastases: risk factors, prognosis, and treatment. A LiverMetSurvey-based study of 6,025 patients. Ann Surg Oncol 2014;21:1276-1286.

[77] Finch RJ, Malik HZ, Hamady ZZ, Al-Mukhtar A, Adair R, Prasad KR, Lodge JP, Toogood GJ: Effect of type of resection on outcome of hepatic resection for colorectal metastases. Br J Surg 2007;94:1242-1248.

[78] Takayama T, Makuuchi M: Intraoperative ultrasonography and other techniques for segmental resections. Surg Oncol Clin N Am 1996;5:261-269. 
[79] Kuhry E, Schwenk W, Gaupset R, Romild U, Bonjer J: Long-term outcome of laparoscopic surgery for colorectal cancer: a cochrane systematic review of randomised controlled trials. Cancer Treat Rev 2008;34:498-504.

[80] Hoekstra LT, Busch OR, Bemelman WA, van Gulik TM, Tanis PJ: Initial experiences of simultaneous laparoscopic resection of colorectal cancer and liver metastases. HPB Surg 2012;2012:893956.

[81] Stanciulea O, Eftimie M, David L, Tomulescu V, Vasilescu C, Popescu I: Robotic surgery for rectal cancer: a single center experience of 100 consecutive cases. Chirurgia (Bucur) 2013;108:143-151.

[82] Alexandrescu S, Diaconescu A, Grigorie R, Ionel Z, Hrehoret D, Brasoveanu V, Ionescu M, Popescu I: Surgical treatment of colorectal liver metastases-a single center experience over 20 years. J Transl Med Res 2015;20:222-232.

[83] Simillis C, Constantinides VA, Tekkis PP, Darzi A, Lovegrove R, Jiao L, Antoniou A: Laparoscopic versus open hepatic resections for benign and malignant neoplasms - a meta-analysis. Surgery 2007;141:203-211.

[84] Topal B, Fieuws S, Aerts R, Vandeweyer H, Penninckx F: Laparoscopic versus open liver resection of hepatic neoplasms: comparative analysis of short-term results. Surg Endosc 2008;22:2208-2213.

[85] Cai XJ, Yang J, Yu H, Liang X, Wang YF, Zhu ZY, Peng SY: Clinical study of laparoscopic versus open hepatectomy for malignant liver tumors. Surg Endosc 2008;22:2350-2356.

[86] Nguyen KT, Gamblin TC, Geller DA: World review of laparoscopic liver resection-2,804 patients. Ann Surg 2009;250:831-841.

[87] Robles R, Marin C, Parrilla P: Laparoscopic liver resection for metastatic disease. Minerva Chir 2008;63:441-453.

[88] Vibert E, Perniceni T, Levard H, Denet C, Shahri NK, Gayet B: Laparoscopic liver resection. Br J Surg 2006;93:67-72.

[89] Geiger TM, Tebb ZD, Sato E, Miedema BW, Awad ZT: Laparoscopic resection of colon cancer and synchronous liver metastasis. J Laparoendosc Adv Surg Tech A 2006;16:5153.

[90] Hayashi M, Komeda K, Inoue Y, Shimizu T, Asakuma M, Hirokawa F, Okuda J, Tanaka K, Kondo K, Tanigawa N: Simultaneous laparoscopic resection of colorectal cancer and synchronous metastatic liver tumor. Int Surg 2011;96:74-81.

[91] Antoniou A, Lovegrove RE, Tilney HS, Heriot AG, John TG, Rees M, Tekkis PP, Welsh FK: Meta-analysis of clinical outcome after first and second liver resection for colorectal metastases. Surgery 2007;141:9-18. 
[92] Chok KS, Cheung TT, Chan AC, Dai WC, Chan SC, Fan ST, Poon RT, Lo CM: Survival outcome of re-resection for recurrent liver metastases of colorectal cancer: a retrospective study. ANZ J Surg 2014;84:545-549.

[93] Wicherts DA, de Haas RJ, Salloum C, Andreani P, Pascal G, Sotirov D, Adam R, Castaing D, Azoulay D: Repeat hepatectomy for recurrent colorectal metastases. Br J Surg 2013;100:808-818.

[94] Carpizo DR, Are C, Jarnagin W, DeMatteo R, Fong Y, Gonen M, Blumgart L, D'Angelica M: Liver resection for metastatic colorectal cancer in patients with concurrent extrahepatic disease: results in 127 patients treated at a single center. Ann Surg Oncol 2009;16:2138-2146.

[95] Elias D, Ouellet JF, Bellon N, Pignon JP, Pocard M, Lasser P: Extrahepatic disease does not contraindicate hepatectomy for colorectal liver metastases. Br J Surg 2003;90:567574 .

[96] Elias D, Gilly F, Boutitie F, Quenet F, Bereder JM, Mansvelt B, Lorimier G, Dube P, Glehen O: Peritoneal colorectal carcinomatosis treated with surgery and perioperative intraperitoneal chemotherapy: retrospective analysis of 523 patients from a multicentric French study. J Clin Oncol 2010;28:63-68.

[97] Mohamed F, Cecil T, Moran B, Sugarbaker P: A new standard of care for the management of peritoneal surface malignancy. Curr Oncol 2011;18:e84-e96.

[98] Adam R, de Haas RJ, Wicherts DA, Vibert E, Salloum C, Azoulay D, Castaing D: Concomitant extrahepatic disease in patients with colorectal liver metastases: when is there a place for surgery? Ann Surg 2011;253:349-359. 
